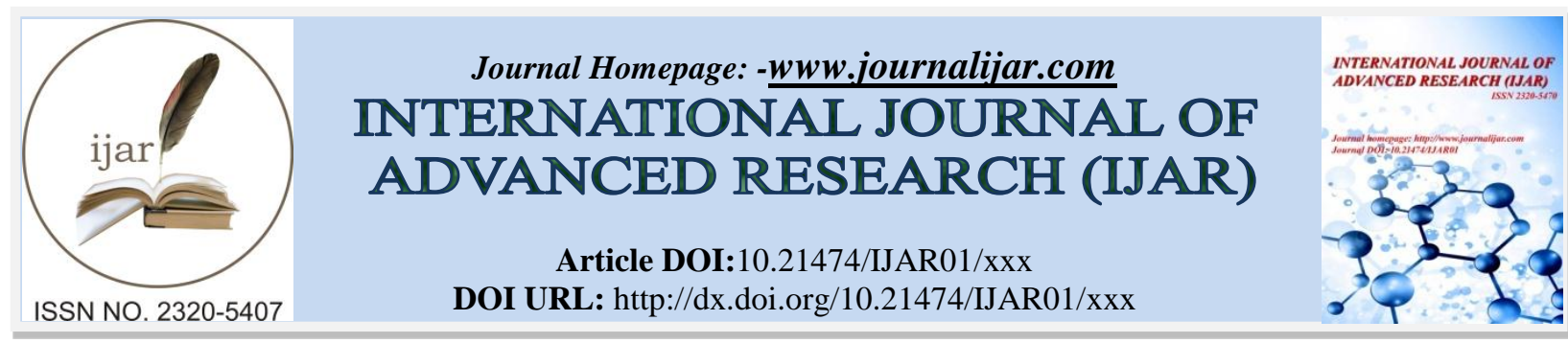

RESEARCH ARTICLE

\title{
RELIGIOUS SELF-REGULATION OF SENIOR HIGH SCHOOL STUDENTS OF CATHOLIC HIGH SCHOOLS IN ILOCOS REGION, PHILIPPINES AND THEIR SUNDAY EUCHARISTIC CELEBRATION ATTENDANCE.
}

\author{
Damianus Abun $^{1}$, Theogenia Magallanes ${ }^{2}$, Jecel Mansueto ${ }^{3}$, Fredrick Agoot $^{4}$ and Jean R. Barroga ${ }^{5}$. \\ 1. Ph.D Faculty of the College of Business of Divine Word College of Vigan. \\ 2. Ed.D, Faculty of the College of Teachers Education of Divine Word College of Vigan. \\ 3. MA, faculty of the College of the Religious Education of Divine Word College of Vigan. \\ 4. MAME, Faculty of the College of Teachers Education of Divine Word College of Vigan. \\ 5. Ed.D, Faculty of the College of Teachers Education of Divine Word College of Vigan.
}

\section{Manuscript Info}

(...........................

Manuscript History

Received: $x x x x x x x x x x x x x x x$

Final Accepted: $x x x x x x x x x x x x$

Published: $\operatorname{xxxxxxxxxxxxxx}$

Keywords:-

Religious self-regulation, identified self-

regulation, introjected self-regulation.

\section{Abstract}

The study was to determine the relationship between religious selfregulation of students and their attendance on Sunday Eucharistic celebration using the concept of extrinsic motivation in terms of religious identified self-regulation and religious introjected selfregulation. The study used descriptive research design and explanation research. In order to carry out the study, questionnaires were used and adapted from SRQ_R (self-regulation Questionnaires: Religious) made by SDT or self-Determination Theory (n.d) and Ryan, Rigby, \& King, (1993). The respondents of the study were 490 Senior High School students from Ilocos Region, Philippines. The study found that religious identified self-regulation and religious introjected selfregulation is high. However, taken as a whole, there was no correlation between religious self-regulation and attendance on Sunday Eucharistic celebration. But taking it singly, there is a correlation between religious identified self-regulation and attendance on Sunday Eucharistic celebration.

Copy Right, IJAR, 2018,. All rights reserved.

\section{Rationale:-}

In the previous research that I conducted on the relationship between religious activities and the moral life of College students in Ilocos Sur (Abun, 2014) found that there was a relationship between religious activities and the moral life of students. This finding implied that religious activities really translate into the change of behaviors, from being immoral to be moral. Religious person means that he/she is moral person. The finding raised a question in the mind of the researcher as the reason why a person engages in religious activities.

It cannot be denied that many students are engaging into religious activities and many also are not engaging in religious activities. Some are devoted and some are not. The question is why there are behavioral differences. Answering such question lead to the motivation of each individual students. It is a fact that behaviors are motivated. Thus, the answer to such question can only be achieved through the investigation of motivation of different students on the reason why some are engaging and some are not or some are devoted and some are not. It is along this concern, this research is conducted. The investigation will focus on the motivation of students using the concept self-determination theory (SDT) on self-regulation. SDT is a well-grounded and empirically validated general theory 
of motivation and personality, which has been under development since Allport's seminal work (e.g., Deci, 1971). Kirkpatrick and Hood (1990) for instance, stated that "a serious approach to researching the topic of motivation for religious involvement ... should begin with a rich psychological theory of human motivation"

\section{The Importance of the Study:-}

This research is directive and illuminative in nature. It is directive because the output of this research will advise the administrators of the school on what should be done to address the situation. It is also an illuminative because the study would dig deeper into the reasons why students are engaging and are not engaging in religious activities based on the concept of Self-Determination Theory. From understanding the reasons, administrators can consider reorienting the students about the nature of religious activities. This study can help the students to assist themselves in correcting their attitude and behavior related to religious activities.

\section{Theoretical Framework:-}

The theory of study states that all behaviors are motivated extrinsically and intrinsically. One engages in activity because of external reasons such as pressures from parents, peers, cultures/religions and fear of punishment or praise. However, it is not also true that all people are extrinsically motivated, there are many people out there who engage in activity because they themselves see the importance of the activity, and it is enjoyable and is beneficial. No body and external pressure forces them to go into certain activity.

\section{Understanding Religion and Religious Behaviors:-}

According to McCulough and Carter (2013) as cited from James (1958), Pratt (1934) and Atran and Norenzayan (2004) religion is a deeply held beliefs as well as the emotions and behaviors that accompany such beliefs. The belief is originated in the awareness of the existence of supernatural agents such as gods and spirits that are presumed to play an important role in human affairs. Following this definition, religion is a form of an acceptance to the existence of the supernatural. The acceptance of the existence of the supernatural is accompanied by the proper behavior demanded by such belief.

Religion becomes relevant and important because it affects the behavior of those who believe in it. Studies have shown that individual differences in religiosity are related to a wide array of behaviors and outcomes such as longer life (McCullough, Hoyt, Larson, Koenig \& Thoresen, 2000), fewer depressive symptoms (Smith, McCullough, \& Poll, 2003), higher level of pro-social behaviors (Pichon, Bocato, \& Soroglou, 2007), less crime, delinquency, and drug use (Baier \& Wright, 2001) and even higher school achievement (Jeynes, 2002). These positive consequences are as the result of living according to the requirement of such beliefs. It has been hypothesized that religion fosters the development and the exercise of self-control and self-regulation which lead to beneficial outcomes.

However the investigation on the motivation of religious behaviors can help us understand why people behave religiously. The study of Allport (1950) tried to find out the extrinsic and intrinsic motivation for religion in which he found that religious motivation is related to extrinsic motivation. This study was also followed up by the study of Gorsuch, Mylvaganam and Gorsuch (1997) about the extrinsic and intrinsic motivation for religion. According to Allport and Ross (1967) that individuals described by extrinsic religiousness use their religion to fulfill more basic needs such as social relations or personal comfort, but "the embraced creed is lightly held or else selectively shaped to fit more primary needs".

\section{Understanding of self-regulation:-}

Despite considerable research in the field, definition of self-regulation remains a difficult one. It is a multidimensional construct which is composed of motivational, cognitive, behavioral, and affective functions (Grolnick \& Farkas, 2002). It also becomes complex because the conceptualizations of self-regulation differs according to the theoretical viewpoint of the researcher, leading to the assessment of different aspects of this important construct. Behavioral theories of self-regulation, for example, focus on learned self-control, where motivation by rewards, and children's development of strategies to manage their reactions to gain such rewards, lead to self-regulated behavior (Bronson, 2000). In this case, self-regulation is the ability of the person to regulate his/her behavior based on his/ external motivation.

In line with the above concept, research consistently shows that self-regulation is considered a skill which is necessary for reliable emotional well- being. Emotional well-being is determined by how the person manages his/her life. It makes a different from one's well-being to another person's well-being. The emotional well-being of the 
person who controls his/her own life is different from the one whose life is controlled by others or external forces/regulators. A true happy person is the one who is free to act based on his own values and free will. Behaviorally, he/she acts based on his/her own best interest, consistent with his/her deepest values in which violation of one's deepest values causes guilt, shame, and anxiety, which undermine well- being. Emotionally, selfregulation is the ability to calm yourself down when you're upset and cheer yourself up when you're down ( Stosny, 2011). He emphasized that we need to improve our self-regulation skill and a good place to start is an understanding of the biology and function of emotions in general and specifically feelings. Emotions move us. The ancients believed that emotions move behavior; in modern times we say they motivate behavior. They energize us to do things by sending chemical signals to the muscles and organs of the body; they prepare us for action.

\section{By having Self-regulation skill:-}

one has the ability to monitor and control his/her own behavior, emotions, or thoughts, altering them in accordance with the demands of the task. It can boost the capability of the person to inhibit responses, to resist interference from irrelevant stimulation, and to persist on relevant tasks even when one doesn't enjoy them (Cook \& Cook, 2009). By continuing to improve self-regulation skill, one can reach the level of maturity in terms of self-regulation. According to Cook and Cook (2009), mature self-regulation requires several sophisticated cognitive skills. These include awareness of the demands of any given situation; consistent monitoring of one's own behavior, thoughts, and strategies; consideration of how successfully one is meeting the demands of the situation; and the ability to change aspects of his/her current functioning as needed to fit the situation or to accomplish a goal. According to studies, aspects of self-regulation correlate with various positive outcomes for children and adolescents-including better academic performance, problem-solving skills, and reading comprehension; more satisfying interactions with peers; higher levels of intrinsic motivation, self- worth, perceived competence, self-efficacy, moral cognition, and moral conduct; fewer behavior problems; and lower levels of psychopathology, such as depression (Eisenberg, Smith, Sadovsky, \& Spinrad, 2005, Shonkoff \& Phillips 2000)..

After we have presented those ideas, now we cannot deny but to acknowledge that self-regulation is important because it helps a person to know who really directs their behavior and their life. All human people have given the reason or the ability to know and therefore their behavior must be guided by their own reason and their free will, not by other people and the society. Many believes that most societal problems are caused by poor self-regulation including underachievement in academic performance (Reis \& Greene, n.d).

\section{Components of Self-Regulation according to Self-Determination Theory (SDT):-}

Self-Regulation is composed of external, introjected, identified, integrated regulation and intrinsic motivation. But to serve the purpose of the current study, there will be four components discussed such as external, introjected, identified regulation and intrinsic motivation. These components are elements of extrinsic motivation. However, in order to understand the extrinsic motivation, intrinsic motivation is part of the discussion.

\section{External regulation:-}

The main question here is why people do certain things and not the other things. The reasons why a certain person does one thing but not the other thing are related to different kind of motivation of different people (Deci, \& Ryan, 2000). Deci and Ryan have investigated the reason behind why a person is so passionate in certain activity but not in other activity. Their investigation leads to different motivation as the reason why a person acts. Motivation refers to the drive or reason for doing something. Without it, one would have no inspiration, and one would not accomplish what he/she wants to accomplish (Deci, \& Ryan, 1985). It makes the difference between the motivated and the demotivated person. The motivated person can accomplish his/her goal, while the demotivated person cannot accomplish. It is a key when it comes to getting people to take action.

Source of motivation is intrinsic and extrinsic. Intrinsic motivation is taking some action or accomplishing one thing because he/she finds that by doing such thing he/she finds enjoyment or pleasure or make him happy. The motivation for acting is found in the action itself and the person himself/herself, and not in some external forces. The self-autonomy can be achieved when individuals feel they are engaging in activity because they choose to do so, not because they feel pressured by other people (parents, teachers) or other external factors. Extrinsic motivation is contrary to intrinsic motivation. The source of motivation is something external to the person. Though the decision to act is made by the person, but such decision is not originated from within the person but from something external to the person such as reward or punishment. When one acts based on intrinsic motivation, he/she is doing something because he/she likes it, it is fun, he/she enjoys it, or he/she finds it pleasurable. While extrinsic motivation, one does 
certain thing because of reward or fear for punishment, even though the act does not give him/her happiness or pleasure. One is not acting on his/her own free will. The one that regulates the behavior is not the person himself/herself but it is external forces or demands such as praise and punishment that come from parents, society or social group. The person is not in control of and cannot alter his/her actions, thoughts and feelings except to comply. In this case, there is no autonomy. Autonomous behavior comes from one's sense of self, unlike controlled behavior that comes from outside pressure. Self-determination may well be the most powerful factor in becoming a welladjusted person (Mclean, 2006).

In line with the theory of motivation, self-regulation is a deliberate effort done by a person to alter its own states and responses, including behavior, thoughts, impulses or appetites, emotions, and task performance. However, such selfregulation can be motivated either by the person himself/herself or pressure from society or culture. Behaviorally, the person acts on certain thing, either because he/she likes it or because other people, external environment, society or culture requires it. The behavior is learned by the person through the society where he/she is living. The problem arises when comparing human to animal because animal learn certain pattern of behavior, not because it likes the act but because of fear of punishment.

Previous research on the animal concluded that animals learn behaviors based on past rewards and punishments. In that way, behavior patterns are molded by the external environment (Psychology,n.d). However, Bandura, a behaviorist, argued that shaping human behavior is more complex than animal. If animal is more on external regulation but human is external and internal at the same time. On the one hand, Bandura argued that the environment plays a greater role in shaping our behavior than genetics and at the other hand Bandura (1986, 1996) argued that there are several factors shaping our behavior and the first is self-observation. By observing the behavior of others and learn the consequence of those behaviors, one can learn certain pattern of behaviors. "Most human behavior is learned observationally through modeling: from observing others, one forms an idea of how new behaviors are performed, and on later occasions this coded information serves as a guide for action." We regulate our behavior by monitoring the behavior of others and consequence of those behaviors and adjusting our behavior accordingly. Second is judgmental process. It is a subjective evaluation of the consequences of our behavior. A person will always evaluate the consequence of his/her behavior without referring it to others or external rules (personal standards), and make some adjustment to his/her behavior. It is almost impossible to regulate a behavior effectively without monitoring its consequences. Poor monitoring is the main cause of self - regulation failure. $\mathrm{He} / \mathrm{she}$ can also evaluate his/her behavior based on prescribed standards of behavior (standard of reference). In other words, the behavior of the person is directed by his/her own will.

Beyond self-observation and judgmental process, other psychologists confirm that self-regulation can be considered from both behavioral and neural systems levels, and from developmental traditions that have historically devoted greater attention to either (a) emotion-related processes of reactivity and regulation or (b) cognitive processes, including children's working memory and attention deployment (Blair \& Razza, 2007). There is consensus across these diverse disciplinary perspectives that children's self-regulation includes their ability to manage or modulate positive and negative emotions, to inhibit or control their behavior, and to shift and focus their attention (Blair, 2002; Cole, Martin, \& Dennis, 2004; Eisenberg et al., 1996; Kochanska, Murray, \& Coy, 1997; Kopp, 1989; Mischel, Ebbesen, \& Zeiss, 1976). Their ability to modulate their behavior can be externally and internally influenced.

Now we know where the behavior comes from. In short, in external regulation, the behavior of the person is not motivated by the person himself/herself but it is externally motivated. The person behaves to gain to some rewards or to avoid some negative contingency. Example, someone does regular exercise to lose weight but the purpose is to get prize or to be recognized. A student who is doing well in academic is because his/her parents will buy for him/her a new car. Therefore, the behavior is controlled by external incentives such as praise, rewards, and punishment avoidance.

\section{Introjected regulation:-}

The reasons for acting are always different from one person to another person because of different sources of motivation. Motivation for acting varies from one individual person to another; one has intrinsic motivation, while others have extrinsic motivation. Contrary to the external regulation wherein a person acts out of fear of punishment or reward, and obedience, introjected regulation is behaving out of a sense of guilt or obligation or a need to prove something. One is behaving in a certain way because he/she has to do it, not because he/she wants to do it or one wants to be recognized. It involves the internalization of external controls, which are then applied through self- 
imposed pressures in order to avoid guilt or to maintain self-esteem (Deci \& Ryan, 1999). It is a controlling motivational regulation in which people act due to internal pressures that are regulated by contingent self-esteem (Ryan \& Deci, 2000). One is taking on external regulations to behavior but not fully accepting said regulations as his/her own. The motivation is still extrinsic motivation; however, such extrinsic motivation has been adopted but not yet incorporated by the person into the sense of self. The behavior rather than being externally controlled becomes internally controlled. However, at this stage the behavior is extrinsically motivated as it is used in order to achieve another goal rather than for the joy of participation (Cox. 2007).

Introjected regulation indicates that people go along with a task because they think they should and feel guilty if they don't. Such regulation might include studying for exams, doing homework, physical exercise or visiting a sick relative or elderly parent because he/she thinks that he/she should or ought to do it, not because he/she wants to do it (Positive Psychology Resources, 2006). Though the control is still with the person who committed the act, however, the act is not really the act of free-will and because he/she wants to do it but he/she does it because it is an obligation or a duty to do or else they would be ashamed. He acts because of pride, shame or guilt. Taking another example is losing weight because one feels that obesity is a character flaw. Obesity in the mind of many people is bad. Introjected regulation occurs when the external contingencies have been internalized and the individual acts to facilitate self-esteem (e.g. exhibit ability) or lessen guilt and avoid demonstration of failure.

\section{Identified regulation:-}

Identified regulation is behaving because of the importance one ascribes to the behavior. One is doing regular exercise because it is important for his/her health. At this level, the action begins to be integrated within the person's sense of self. Identification involves a conscious acceptance of the behavior as being important in order to achieve personally valued outcomes. It is a more autonomously driven form of extrinsic motivation (Deci, Ryan \& Williams, 1996). It involves consciously valuing a goal or regulation so that said action is accepted as personally important. It is no longer external pressure on the person to perform such act but he/she does it because he/she is aware of its importance and at the same time finds pleasure and enjoyment pursuing such behavior or activity. Another example is losing weight because a healthy weight is an important goal to accomplish. Or students who finish their assignments because they know that it is important for them to finish their assignments and they want to learn. In the identified regulation, it is no longer outside forces that motivate them to do certain thing but the person himself/herself and the value of the act itself. The act is good in itself.

The person acts on certain thing when the person sees it important for him/her. This happens when the behavior or act is explicitly recognized and valued by the individual (high perceived value and personal importance). At the identified regulation level, the person himself/herself motivates himself/herself to do certain things because of its value for the person himself/herself (Vlachopoulos \& Karageorghis, 2005). The person must be able to make his/her decisions which values and rules to embrace, not depending on their parents or society where he/she lives.

\section{Intrinsic motivation:-}

Intrinsic motivation is the inner passion of an individual person to pursue certain activity that what he/she believes giving him/her pleasure. In other words, intrinsic motivation is an energizing of behavior that comes from within an individual, out of will and interest for the activity at hand. No external rewards are required to incite the intrinsically motivated person into action. The reward is the behavior itself. In the Self-determination theory, intrinsic motivation represents the most self-determined or autonomous behavior regulation by inherent interest, enjoyment and satisfaction. There are three types of intrinsic motivation according to Deci and Ryan, (2000):

1. Intrinsic motivation toward knowledge is observed if an activity is performed for the pleasure or satisfaction of learning or understanding something.

2. Intrinsic motivation toward accomplishment is defined as engaging in an activity for the pleasure of accomplishing or creating something.

3. Intrinsic motivation toward stimulation occurs when an activity is performed to obtain stimulating experiences. In relation to other activities, previous studies have found that intrinsic motivation have been associated with interest, excitement, confidence, enhance performance, persistence, creativity, self-esteem, and general well-being (Ryan \& Deci, 2000). However, in terms religious activities seemed to be motivated by extrinsic motivation. Along this concern, the current study is to find out the reason why some students engage in religious behavior, and some are not. 


\section{Conceptual Framework:-}

The conceptual framework illustrates the independent variables and dependent variables. It reflects the correlation between the independent variable and dependent variable. Self-regulation in terms of introjected and identified regulation affects the Sunday Eucharistic Celebration.

Independent Variables

\section{Religious Self-regulation:}

Identified Self-regulation

\section{Introjected Self-regulation}

Dependent Variable

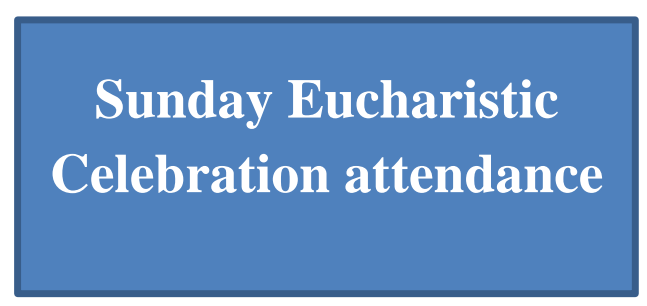

Figure 1:- explains the relationship between religious self- regulation and attendance on Sunday Eucharistic celebration.

\section{Statement of the Problems:-}

The statement of the problem of the study is drawn from the conceptual framework. This study is to determine the level of self-regulation of students and its influence on their Sunday Eucharistic Celebration attendance.

It specifically answers the following questions:

1. What is the religious self-regulation of Senior High School students of Divine Word College in Vigan in terms of

1. Identified Regulation

2. Introjected Regulation.

2. What is the level of Sunday Eucharistic Celebration attendance of Senior High Students of Divine Word College of Vigan?

3. Is there a relationship between self-regulation and Sunday Eucharistic Celebration?

\section{Assumption of the Study:-}

1. The questionnaires of the study are valid and reliable.

2. The respondents are answering the questionnaires objectively and honestly

3. Methodologies are correct

\section{Hypothesis:-}

Studies have shown that individual differences in religiosity are related to a wide array of behaviors (McCullough, Hoyt, Larson, Koenig \& Thoresen, 2000). According to Allport and Ross (1967) that religious behaviors are influenced by extrinsic motivation and therefore the study hypothesizes that there is a relationship between religious self-regulation and the Sunday Eucharistic Celebration attendance.

\section{Scope and Delimitation of the Study:-}

The study is only to determine the level of self-regulation of Senior High School students in terms of introjected and identified self-regulation and its effect on Sunday Eucharistic Celebration attendance. It covers only the Catholic Senior High School students in Ilocos region. The study limits its investigation only on introjected and identified self-regulation because according to the instruction of Religious Self-Regulation Questionnaires (SRQ-R) that these two variables represent the dynamically meaningful reasons why people engage in religious behaviors and that the external regulation and intrinsic motivation do not add to the validity of the self-regulation scale (Self-Determination Theory (SDT), n.d.).

\section{Review of Related Literature and Studies:-}

The literature and studies that are reviewed in this study are related to the concept self-regulation and how they affect he behavior of a person. 


\section{Related Literature:-}

A social psychologist, Baumeister (2007), contends that there are four components of self-regulation theory and they are standards of desired behavior, motivation to meet the standards, monitoring of situations and thoughts that precede breaking said standards and will power. In order to achieve certain goal or objective, one has to apply the desired behavior to achieve such goal. Example is a student who wants to be in the dean's list has to study smartly or read a lot of books. Or a person who wants to have an excellent health condition has to take the right food, regular exercise and take vitamins. Those are the desired behavior to achieve a good health condition. In order to carry out those desired behaviors, one should have the motivation. Correct motivation is needed to sustain the behavior to achieve the goal. Beside motivation, one should monitor the situation by which standards of desired behavior can be broken. Often times, though one wants to keep going and maintain the regular activity or behavior but there are situations in which those regular behaviors cannot be maintained because of uncalculated situations that occur along the way. One cannot continue doing exercise due to some situations that prevent the regular behaviors to continue. Lastly is the will power. One may plan to achieve the goal, try to work hard and monitor the situation but one needs to have a will power to sustain them because if there is no will power or inner strength to stick it out, the goal cannot be attained.

In line with the components of self-regulation behavior, Bandura (1991) argued that the major self-regulative mechanism operates through three principal sub-functions and these include monitoring one's own behavior, its determinants and its effects, judgment of one's behavior in relation to personal standards and environmental circumstances, and affective self-reaction. In terms of self-monitoring, according to Bandura (1991), people cannot influence their own motivation and action very well if they do not pay adequate attention to their own performances, the conditions under which they occur, and the immediate and distal effects they produce. In this case, one needs to monitor the performance if it is still on the right tract as expected, then the situation that affect the performances and the final outcome. One can be motivated to apply the same behavior when the performance outcome is as expected and the conditions are still favorable to support the same kind of behavior. Thus, constant monitoring is necessary to regulate the behavior in order to consistently apply the correct behavior to achieve the final outcome. Success in self-regulation partly depends on the fidelity, consistency and temporal proximity of self-monitoring. Included in the self-monitoring are thought pattern, emotional reactions, and behavior and condition under which these reactions occur and motivation. Self-observation/monitoring provides information needed for setting realistic goals and for evaluating one's progress toward them. Besides monitoring the behavior itself, one has to judge the behavior if the behavior is still within the prescribed standard behavior imposed by himself/herself and as prescribed by society. Consequently, such judgment results to self-reactive influences, in the sense that people will pursue course of action that produce positive self-reaction and refrain from behaving in ways that result in self-censure. One would be satisfied and maintain the behavior that meets that the desired standard as accepted not only by the person but also by the society or influential persons in the society. Though Bandura does not include will power as part of the components of self-regulation behavior but both with Baumeister agree that self-regulation can be achieved by establishing desired standards of behaviors, monitoring of situation or environmental circumstances and selfmotivation in order to attain the self-regulated behavior.

If self-regulation theory of Bandura (1991) and Baumeister (2007) focus much on the individual efforts, however, according Lundy (n.d) self - regulation is not just an individual efforts but it is also a collective efforts. Lundy claims that self-regulation can also be influenced by the system and the structure, the culture and communities where one is living, or learning. Even if one has a self-regulation behavior but such self-regulation behavior cannot be sustained and enhanced if the system, structure, culture of the organization and practices or values of the community do not support. Let us take an example of a school situation. Many schools are exploring ways that classroom design can enhance self-regulation. There's also a growing awareness that self-regulation gets a real boost when the whole school is involved. In this case self-regulation is not just class management problem and the student himself/herself but community or school as a whole. Self-regulation capacities are also strengthened when the family is on board. In a sense that self-regulation is enhanced or strengthened when kids experience consistent expectations and support at home and at school. There must be consistency of practices at home and in the school in order to achieve self-regulation. As the self-regulation movement grows, policies and programs in other sectors can foster self-regulation capacities in kids and adults (Lundy, n.d). Beside system, structure and community, culture is also important for self-regulation enhancement. Self-regulation behavior can be strengthened when the culture where one is working and learning is in harmony with the system, structure and the values of the community. In short, according to Lundy (n.d), self-regulation is the result of the integration of those four different parts. A student can regulate his/her behavior and strengthens those behaviors when those four dimensions are in harmony with 
his/her self-desired behavior standards. Self-regulation cannot be strengthened if those four components are not in consonant. This is a particular challenge for the school to consider on how to create a holistic environment that is supportive for the growth of self-regulation. It is not just about classroom management, but it is also a problem of the school system and structure and the home environment.

Given those components of self-regulation presented above, the question why one has to regulate his/her behavior needs to be investigated. One cannot regulate his/her behavior for nothing but for a purpose. Regulating behavior is a way of achieving one's goals that one wants to achieve. It is the way how the individuals choose to do and how they go about trying to accomplish their goals. Markus and Wurf (1097) distinguished three components of selfregulation process: goal selection, preparation for action and cybernetic cycle of behavior. According to them, the first stage in the self-regulation process is the goal selection stage. Before one can regulate his/her behavior, one must select the goal and decide what one intends to do. After one has set the goal, now one has to prepare a plan for action. In this stage, one has to design and prepare to implement the plan to achieve the goal. Lastly is cybernetic cycle of behavior. It is a process of how one uses information that he/she gathers in the process of executing the plan to regulate his/her behavior. Usually after one sets the goal, then he/she examines his/her behavior and compare if his/her behavior is leading toward the attainment of the goal. After obtaining the information, one has to adjust his/her behavior to reduce the discrepancy between the goal and the behavior; some adjustments have to be made.

Though setting goal for one's self is pre-requisite for self-regulation, however, the attainment of goal can be affected by other factors such as self-efficacy, possible self-image, and self-awareness (Bandura, 1986, 1989). Self-efficacy is about one's own belief toward his/her capability to do certain task. People with high self-efficacy beliefs think they have the ability to do the task, to handle the problems encountered along the process, and to reach their objectives. While people with low self-efficacy beliefs doubt their ability to succeed and do not believe they have what it takes to reach their goals. Beside self-efficacy, onother factor that influences self-regulation is a dream of future possible self. It is about one's ideas about what he/she may be like in the future (Markus \& Nurius, 1986; Markus \& Ruvolo, 1989). Additional important component of the self-regulation is self-awareness. Self-awareness means that one is capable of taking himself/herself as the object of his/her own attention. Knowing one's self is another factor that can influence self-regulation. Duval and Wicklund (1972) argued that when people focus their attention inward (i.e., when they become self-aware), they tend to compare their present state with a relevant standard. Positive emotion arises when people believe they are meeting or exceeding a relevant standard; negative emotion arises when people believe they are falling short of a relevant standard.

\section{Related Studies:-}

There were many studies conducted related to self-regulation, psychological needs, motivation and academic performance, religion and self-regulation and self-control, religion and self-regulation, involvement in religion and self-regulation and with other aspects of life. Those studies pointed out the essential point that self-regulation have affected the extent of behavior of individual persons in pursuing certain activity.

Vlachopoulos and Karageorghis (2005) conducted a study on interaction of external, introjected and identified regulation with intrinsic motivation and its correlation with exercise enjoyment. The study found a significant interaction between identified regulation and intrinsic motivation with exercise enjoyment. Specifically, the coexistence of high levels of identified regulation with high levels of intrinsic motivation corresponded with higher scores on exercise enjoyment. Wilson, Rodgers, Blanchard and Gesell (2003) also conducted a study on the relationship between psychological needs, self-determined motivation, exercise attitudes and physical fitness. The purpose of the study was to determine the relationship between psychological need satisfaction, exercise regulation and motivational consequences proposed by Self-Determination Theory (SDT) of Deci and Ryan (1985, 2000). Results indicated competence and autonomy were positively correlated with more self-determined exercise regulations, which in turn were more positively related to exercise behavior, attitudes, and physical fitness

As a follow up from those studies, Wilson and Rogers (2008) conduct a similar study on the relationship betwe $\mathrm{n}$ perceived psychological need satisfaction and behavioral regulation in exercise. The study was intended to find out if psychological need satisfaction plays a role in the motives regulating exercise behavior. The study concluded that greater perceived psychological need satisfaction predicted endorsement of more self-determined exercise regulations in the structural equation modeling analysis. Wilson, Longley, Muon, and Rodgers (2006) studied on the contributions of perceived psychological need satisfaction to well-being in exercise. These results suggest that perceived psychological need satisfaction in exercise contributes to global and contextual well-being. 
While studies on psychological need satisfaction and participation on physical exercise, physical well-being found to be interrelated, Koh, Tan, Tan, and Fang (2010) conducted a study to find out the effect of motivation of students and academic performance. The findings suggest that the students perceived their psychological needs to be satisfied and had high levels of self-determined motivation and there is a correlation between psychological need satisfaction and academic performance. Ayub (2017) also pursued a similar study on the effect of intrinsic and extrinsic motivation on academic performance. Samples of 200 students of selected university in Karachi were taken. Results of the study suggest that intrinsic and extrinsic motivation and academic performance were positively correlated. The study concluded that motivation improves academic performance of the students and there is a gender difference in motivation type and academic performance.

In terms religion and self-regulation, McCullough and Willoughby (2009) conducted a study on the relationship between religion and self-regulation and self-control. They concluded that religion can promote self-control, influence how goals are selected, pursued, and organized; facilitate self-monitoring; foster the development of selfregulatory strength; prescribe and foster proficiency in a suite of self-regulatory behaviors; and that some of religion's influences on health, well-being, and social behavior. Within the same interest, Koole, Meijer and Remmers (2017) pursued a similar study on religious rituals and self-regulation. They concluded that religious rituals may have important benefits for self-regulation. According to the study Religious rituals may facilitate not only effortful self-control among their practitioners, but also implicit forms of self-regulation, and improve the alignment between explicit and implicit processes. Through these multiple routes, religious rituals may function as tools for adaptive self-regulation. Such finding is supported by Rounding, Lee and Jacobson (2012) that the emergence of religion is a cultural adaptation necessary for promoting self-control. Further, they argue that religious concepts result to higher level of self-control. A review of the empirical literature confirmed that religious stimuli and practices foster implicit self-regulation, particularly among individuals who fully internalized their religion's standards. The literature review suggests that some seemingly irrational aspects of religion may have important psychological benefits by promoting implicit self-regulation (Koole, et. al. 2009).

Though those studies presented above have no direct discussion on self-regulation and religious behavior, however those studies gives us ideas that self-regulation such as external regulation, introjected regulation, identified regulation and intrinsic motivation affect the behavior of a person in pursuing certain activity. Other studies pointed out the existence of correlation between religion and self-regulation (McCullough \& Carter, 2013). The study of Allport and Ross (1967) found the correlation between extrinsic motivation and religious motivation. Such study was also confirmed by the study of Gorsuch (1994) and Pierce, et.al (2005).

Research Methodology

In order to carry out the study, the appropriate research methodology is utilized. Therefore, this part will discuss research design, data gathering instruments, population, locale of the study, data gathering procedures and statistical treatment of data.

\section{Research Design:-}

The study is a quantitative descriptive research design and explanation research to determine the level of religious self-regulation of students. It describes and explains what is found in the data. It involves the description, recording, analysis and interpretation based on the data gathered through questionnaires which are statistically computed. It is a fact finding with adequate interpretation. It assesses, determines and reports the way things are. In other words, it describes the data that have been collected on research sample, describes "what is" about the data gathered.

In line with the current study, the descriptive correlational research design was deployed. The study assessed the religious self-regulation level of students and how it affects the Sunday Eucharistic Celebration Attendance. This was to identify what the dominant religious self-regulations among students were and what particular self-regulation does affect the Sunday Eucharistic celebration attendance.

\section{Locale of the Study:-}

The locale of the study was the Catholic Senior High Schools run by the Catholic Church located in Bangui, Pagudpud, Batac and Divine Word College of Vigan Senior High School. Those schools are located in Ilocos Norte and Ilocos Sur. 


\section{Population:-}

The population of the study was composed of 490 Senior High School students of Catholic High School in Ilocos region. The numbers were determined by Slovine's Formula:

$\mathbf{n}=\underline{\mathbf{N}}$

$1+\overline{\mathbf{N e}}{ }^{2}$.

\section{Data Gathering instruments:-}

The study utilized questionnaires. The questionnaires were adapted from SRQ_R (self-regulation Questionnaires: Religious) made by SDT or self-Determination Theory (n.d) and Ryan, Rigby, \& King, (1993). The questionnaires were distributed to selected Catholic Senior High School students in Ilocos Region. Questionnaires were composed of three parts and they are introjected regulation, identified regulation and Sunday Eucharistic Celebration Attendance.

\section{Data Gathering Procedures:-}

In the process of data gathering, the researcher sent letters to the Principals of the schools, requesting them to allow the researcher to flow his questionnaires in his/her school. The retrieval of questionnaires was arranged between the schools' representative and the researcher with the help of employees and faculty of the schools.

\section{Statistical Treatment of Data:-}

In consistent with the study as descriptive research, therefore descriptive statistics is used to measure the weighted mean and the Pearson $r$ will be used to measure their correlations.

The following ranges of values with their descriptive interpretation will be used:

$\begin{array}{lll}\text { Statistical Range } & \text { Descriptive interpretation } & \text { Overall Descriptive Rating } \\ 4.21-5.00 & \text { Very true } & \text { Very High } \\ 3.41-4.20 & \text { True } & \text { High } \\ 2.61-3.40 & \text { Somewhat true } & \text { Moderate } \\ 1.81-2.60 & \text { Not true } & \text { Low } \\ 1.00-1.80 & \text { Not at all true } & \text { Very Low }\end{array}$

\section{Findings:-}

The findings of the study are presented according to the sequence of the statement of the problems of the study. This study was to determine the level of religious self-regulation of students and its influence on their attendance in Sunday Eucharistic Celebration. It specifically answers the following questions:

Problem 1a. What is the religious self-regulation of Senior High School students of Divine Word College in Vigan in terms of

\section{Identified Regulation:-}

Table 1a:- Level of religious self-regulation in terms of Identified regulation

\begin{tabular}{|l|l|l|}
\hline \multicolumn{1}{|l|}{$\begin{array}{c}\text { 1. One reason I think it's important to actively share my faith with others is } \\
\text { because God is important to me and I'd like other people to know about Him too }\end{array}$} & 4.50 \\
\hline $\begin{array}{l}\text { 2. When I turn to God, I most often do it because I enjoy spending time with him. } \\
\text { 3. When I turn to God, I most often do it because I find it satisfying to me }\end{array}$ & 3.78 & $\begin{array}{l}\text { VT/VH } \\
\text { (T/H) }\end{array}$ \\
\hline 4. One reason I think praying by myself is important is because I enjoy praying & 4.22 & T/H \\
\hline $\begin{array}{l}\text { 5. One reason I think praying by myself is important is because I find prayer } \\
\text { satisfying }\end{array}$ & 3.84 & VT/VH \\
\hline $\begin{array}{l}\text { 6. An Important reason why I attend church is because by going to church I learn } \\
\text { new things }\end{array}$ & 4.07 & T/H \\
\hline Overall & $\mathbf{3 . 9 7}$ & T/H \\
\hline
\end{tabular}

Legend:-

$\begin{array}{lll}4.21-5.00 & \text { Very true } & \text { Very High } \\ 3.41-4.20 & \text { True } & \text { High }\end{array}$




$\begin{array}{lcc}2.61-3.40 & \text { Somewhat true } & \text { Moderate } \\ 1.81-2.60 & \text { Not true } & \text { Low } \\ 1.00-1.80 & \text { Not at all true } & \text { Very Low }\end{array}$

Based on the data that are presented on the table, it shows that overall rating for religious self-regulation in terms of identified regulation is 3.97 which are interpreted as true or high. It means that students have been consciously accepting that behaving religiously or being a religious person is important in order to achieve personally valued outcome. They have internalized required religious behavior to be their own. They have accepted personally that God is important to them and their personal responsibility is to share their faith to others. They also find that praying is satisfying, enjoyable and attending Church is satisfying and one way of learning new things. Here, students do not behave religiously simply because they feel they should, but rather because they have identified with the value of the religious behavior and see its importance for their self-selected goals (Deci, Ryan \& Williams, 1996).

Problem 1b. What is the religious self-regulation of Senior High School students of Divine Word College in Vigan in terms of

Introjected regulation:-

Table 1b:- Introjected regulation

\begin{tabular}{|l|l|l|}
\hline Introjected Self-Regulation & $\bar{X}$ & DR \\
\hline $\begin{array}{l}\text { 1. One reason I think it's important to actively share my faith with others is } \\
\text { because I would feel bad about myself if didn't. }\end{array}$ & 3.22 & $\begin{array}{l}\text { Somewhat } \\
\text { True/SWT/M }\end{array}$ \\
\hline $\begin{array}{l}\text { 2. One reason I think it's important to actively share my faith with others is } \\
\text { because I want other Christians to approve of me. }\end{array}$ & 3.70 & True (T)/H \\
\hline 3. When I turn to God, I most often do it because I would feel guilty if I didn't. & 3.88 & T/H \\
\hline $\begin{array}{l}\text { 4. One reason I think praying by myself is important is because if I don't, God will } \\
\text { disapprove of me }\end{array}$ & 3.39 & SWT \\
\hline $\begin{array}{l}\text { 5. An Important reason why I attend Church is because one is supposed to go to } \\
\text { church }\end{array}$ & 3.93 & T/H \\
\hline $\begin{array}{l}\text { 6. An Important reason why I attend Church is because others would disapprove of } \\
\text { me if I didn't. }\end{array}$ & 2.73 & SWT \\
\hline Overall & $\mathbf{3 . 4 7}$ & T/H \\
\hline
\end{tabular}

Legend

4.21-5.00

$3.41-4.20$

Very true

True

Very High

$2.61-3.40$

Somewhat true

High

$1.81-2.60$

Not true

$1.00-1.80$

Not at all true

Moderate

Low

Very Low

As shown on the table, it reveals that overall computed mean of introjected religious self-regulations is 3.47 which mean true or high. Such rating indicates that students behave religiously out of sense of guilt or out of obligation. It is not because they want to behave that way but because they have to behave that way. It means that students have internalized external controls, which are then applied through self-imposed pressures in order to avoid guilt or to maintain self-esteem (Deci \& Ryan, 1999). They need to share their faith because it is one of their obligation and they want to be recognized. They pray to God to avoid feeling guilty and to make God happy. They attend church celebration because they are supposed to be doing that and so others would approve them.

Table 2:- Summary

\begin{tabular}{|l|l|l|}
\hline & \multicolumn{1}{|c|}{$\bar{X}$} & DR \\
\hline Identified Regulation & 3.97 & True/High \\
\hline Introjected Regulation & 3.47 & True/High \\
\hline Overall & $\mathbf{3 . 7 2}$ & \\
\hline
\end{tabular}

Legend

4.21-5.00

$3.41-4.20$

Very true

True

Very High

High 


$\begin{array}{lcc}2.61-3.40 & \text { Somewhat true } & \text { Moderate } \\ 1.81-2.60 & \text { Not true } & \text { Low } \\ 1.00-1.80 & \text { Not at all true } & \text { Very Low }\end{array}$

As reflected in the summary table, it appears that overall religious self-regulation of Senior High School students in Ilocos Region are 3.72 which is interpreted as true or high. Taking them singly, it shows that identified selfregulation is higher (3.97) compared to introjected self-regulation (3.47). It indicates that the Senior High School students in Ilocos regions have high identified and introjected self-regulation. High identified religious selfregulation is a positive outlook that needs to be strengthened, while high introjected religious self-regulation is a negative outlook that needs to be corrected.

Problem 2. What is the level of attendance of Sunday Eucharistic Celebration of students?

Table 2:- Eucharistic Attendance

\begin{tabular}{|l|l|l|}
\hline Eucharistic Attendance & $\overline{\boldsymbol{X}}$ & DR \\
\hline I attend Sunday Eucharistic celebration & 3.37 & Sometimes/Moderate \\
\hline Total & 3.37 & Sometimes/Moderate \\
\hline
\end{tabular}

Legend

4.21-5.00

$3.41-4.20$

$\begin{array}{lc}\text { Always } & \text { Very High } \\ \text { often } & \text { High } \\ \text { Sometimes } & \text { Moderate } \\ \text { Seldom } & \text { Low } \\ \text { Never } & \text { Very low }\end{array}$

$2.61-3.40$

$1.81-2.60$

$1.00-1.80$

$$
\text { Never }
$$

As gleaned from the table, it reveals that overall computed mean of students' attendance of Sunday Eucharistic Celebration is 3.37 which means somewhat true or moderate. They are not often or always going to the Church for the Eucharistic celebration on Sunday.

Problem 3:- Is there a relationship between religious self-regulation and attendance on Sunday Eucharistic elebration?

Table 3:- Relationship between religious self-regulation and mass attendance

\begin{tabular}{|l|l|}
\hline Introjected Self-Regulation & 0.1377 \\
\hline Identified self-Regulation & $0.2345^{*}$ \\
\hline As a Whole & 0.1861 \\
\hline
\end{tabular}

*Significant at 0.05 Level

As it is presented on the computation table, it shows that as a whole there is no correlation between religious selfregulation and mass attendance on Sunday. However, taking them singly, it appears that religious introjected selfregulation has no correlation with Sunday Eucharistic celebration attendance, but there is a correlation between religious identified self-regulation and Sunday Eucharistic celebration attendance.

\section{Conclusion:-}

The study was to determine the level of religious introjected self-regulation and religious identified self-regulation and their relationship with their attendance on Sunday Eucharistic celebration. The study found that the Senior High School students in Ilocos Region have high religious introjected and identified self-regulation and somewhat true or moderate attendance on Sunday Eucharistic celebration. It was also revealed that as a whole there is no correlation between religious self-regulation and Sunday Eucharistic celebration attendance. Therefore the hypothesis is rejected. However, taking it singly, there is a correlation between religious identified self-regulation and Sunday Eucharistic celebration attendance.

\section{Recommendation:-}

The study of Allport and Ross (1967) found the correlation between extrinsic motivation and religious motivation. Such study was also confirmed by the study of Gorsuch (1994) and Pierce, et.al (2005) that there is a correlation between extrinsic motivation and religious motivation. Therefore the study recommends that the schools must 
provide training program to increase the awareness of the students related to the importance of religious identified self-regulation. The students should be reoriented about the essence of religion and that religion is a personal response toward the call of God to follow Him.

\section{References:-}

1. Abun, D. (2012). The Effect of Religion toward Moral Values of College Students in Ilocos Sur, Philippines. EInternational Scientific Research Journal Consortium, Vol. IV, Issue-3, 2012

2. Allport, G. W., \& Ross, J. M. (1967). Personal religious orientation and prejudice. Journal of Personality and Social Psychology, 5, 432-443.

3. Allport, G. W. (1950). The individual and his religion. NY: Macmillan.

4. Atran, S., \& Norenzayan, A. (2004). Religion's Evolutionary Landscape: Counter intuition, Commitment, Compassion, Communion. Behavioral and Brain Sciences, 27, 713-770. Doi: 10. 1017/SO140525X04000172

5. Ayub, N. (2017). Effect of Intrinsic and Extrinsic Motivation on Academic Performance. Retrieved from http://www.academia.edu/2599275/Effect_of intrinsic_and_extrinsic motivation_on_academic_performance

6. Baier, C., \& Wright, B.R.E. (2001). "If You Love, Keep my Commandments": A meta-analysis of the effect of religion on crime. Journal of Research in Crime and Delinquency, 38, 3-21. Doi: 10:1177/0022427801038001001

7. Bandura, A. (1986). Social foundations of thought and action. Englewood Cliffs, NJ: Prentice-Hall.

8. Bandura, A. \& Wood, R. E. (1989). Human agency in social cognitive theory. American Psychologist,44, 1175-1184.

9. Bandura, A. (1996). Self-Efficacy: The Exercise of Control. New York: Freeman.

10. Bandura, A. (1986). Social foundations of thought and action: A social cognitive theory. New York: Freeman.

11. Baumeister, R.; Schmeichel, B.; \& Vohs, K. (2007). "Self-Regulation and the Executive Function: The Self as Controlling Agent". Social psychology: Handbook of basic principles

12. Blair C., \& Razza R.P. (2007). Relating Effortful Control, Executive Function, and False Belief Understanding to Emerging Math and Literacy Ability in Kindergarten. Child Development, 78(2):647-663. PubMed.

13. Blair C. 2002. School readiness: Integrating cognition and emotion in a neurobiological conceptualization of children's functioning at school entry. American Psychologist. 57:111-127. PubMed.

14. Bronson, M. B. (2000). Self-regulation in early childhood: Nature and nurture.

15. New York, NY: Guilford Press

16. Casenhiser, D., Shanker, S. \& Stieben, J. (2012). Understanding the Nature of Self-Regulation, Milton \& Ethel Harris Research Initiative, York University, Canada

17. Cohen, A. B., Pierce, J. D., Jr., Chambers, J., Meade, R., Gorvine, B. J., \& Koenig, H. G. (2005). Intrinsic and extrinsic religiosity, belief in the afterlife, death anxiety, and life satisfaction in young Catholics and Protestants. Journal of Research in Personality, 39, 307-324.

18. Cole P. M, Martin S.E,\& Dennis T.A. 2004. Emotion regulation as a scientific construct: Methodological challenges and directions for child development research. Child Development. 75(2):317-333. PubMed.

19. Cook, J.L. \& Cook, G. 2009). Self-Regulation. New York: Prentice Hall

20. Cox, R. H. (2007). Sport Psychology Concepts And Applications (6 ${ }^{\text {th }}$ Edition). New York: McGraw-Hill Companies Inc.

21. Deci, E. L. (1971). Effects of externally mediated rewards on intrinsic motivation. Journal of Personality and Social Psychology, 18, 105-115.

22. Deci, E.L. \& Ryan, R.M. (1999). Intrinsic and Extrinsic Motivations: Classic Definitions and New Directions. Contemporary Educational Psychology 25, 54-67, doi:10.1006/ceps.1999.1020, Retrieved from http://www.idealibrary.com

23. Deci, E.L. \& Ryan, R.M. (1985). Intrinsic motivation and self-determination in human behavior. New York: Plenum Press.

24. Deci, E. L., \& Ryan, R. M. (2000). The 'what' and 'why' of goal pursuits: Human needs and the selfdetermination of behavior. Psychological Inquiry, 11, 227-268.

25. Deci, E.L., Ryan, R.M. \& William, G.C. (1996). Need Satisfaction and the Self-Regulation of Learning. Learning and Individual Differences, Vol.8, No.3, 1996

26. Eisenberg, N., Fabes R.A., Guthrie I.K, Murphy, B.C, Maszk, P., \& Holmgren R. (1996). The relations of regulation and emotionality to problem behavior in elementary school children. Development and Psychopathology. 8:141-162.

27. Eisenberg, N., Smith, C.L., Sadovsky A., \& Spinrad, T.L. (2004). The Relation of Problem Behavior Status to Children's Negative Emotionality, Effortful Control and Impulsivity and Prediction of Change. Retrieved from 
https://www.ncbi.nlm.nih.gov/pubmed/?term=Eisenberg\%20N\%5BAuthor\%5D\&cauthor=true\&cauthor_uid=1 6938090

28. Gorsuch, R.L., Mylvaganam, G \& Gorsuch, K. (2009). Perceived Religious Motivation. The International for the Psychology of Religion. Vol. 7-1997-Issue 4

29. Grolnick, W. S., \& Farkas, M. (2002). Parenting and the development of children's self-regulation. In M. H. Bornstein (Ed.), Handbook of parenting: Volume 5, practical issues in parenting (2ndedn., pp. 89-110). Mahwah, NJ: Lawrence Erlbaum.

30. James, W. (1958). The Varieties of Religious Experience. New York: Penguin.

31. Journal of Applied Social Psychology. DOI: 10.1111/j.1559-1816.2003.tb01890.x Retrieved from http://onlinelibrary.wiley.com

32. Kirkpatrick, L. A., \& Hood, R. W. (1990). Intrinsic-extrinsic religious orientation: The boon or bane of contemporary psychology of religion? Journal for the Scientific Study of Religion,29, 442-462.

33. Kochanska, G., Murray, K., \& Coy K.C. 1997. Inhibitory control as a contributor to conscience in childhood: From toddler to early school age. Child Development. 68(2):263-277. PubMed.

34. Koh, C., Tan, H.S., Tan, K.C., \& Fang, L. (2010). Investigating the Effect of 3D Simulation Based Learning on the Motivation and Performance of Engineering Students. Published in in JEE, The Research Journal for Engineering Students. DOI: 10.1002/j.2168-9830.2010.tb01059.x. Retrieved from http://onlinelibrary.wiley.com.

35. Koole, S. L., McCullough, M.E., \& Kuhl, J. (2009). Why Religion's Burdens are Light: From Religiosity to Implicit Self-Regulation. Personality and Social Psychology Review, Vol. 14, issue 1, 2010.

36. Koole, S.L., Meijer, M. \& Remmers, C. (2016). Religious Rituals and Self- Regulation. Religion, Brain \& Behavior Journal, Vol.7, 2017-issue 3. Doi: 10:1080/2153599X.2016.1156562

37. Kopp, C.B. (1989). Regulation of distress and negative emotions: A developmental view. Developmental Psychology. 25(3):343-354

38. Lundy, T. (n.d.). Self-Regulation: Integrating Four Essential Perspectives. Canadian self-Regulation Initiative. Retrieved from http://www.self-regulation.ca/4-dimensions-of-self-regulation.html

39. Markus, H. \& Wurf, E. (1987). The dynamic self-concept: A social psychological perspective. Annual Review of Psychology, 38, 299-337.

40. Markus, H., \& Nurius, P. (1986). Possible selves. American Psychologist, 41, 954-969.

41. Markus, H., \& Ruvolo, A. (1989). Possible selves: Personalized representations of goals. In L. A. Pervin(Ed), Goal concepts In personality and social psychology (pp. 211-242). Hillsdale, NJ: Erlbaum.

42. McCullough, M.E \& Willoughby, B.L. (2009). Religion, self-regulation and self-Control: Associations, Explanations, and Implications. Psychology Bulletin, Vol 1. 69-93. DOI: 10.1037/a0014213.

43. McCullough, M.E., Hoyt, W.T., Larson, D.B., Koenig, H.G., \& Thoresen, C.E. (2000). Religious Involvement and Mortality: A meta-analytic Review. Health Psychology, 19, 211-222. Doi: 10.1037/0278-6133.19.211. McCullough, M.E, \& Carter, E.C. (2013). Religion, Self-Control and self-Regulation: How and Why are They Related? DOI:10.1037/14045-006, APA Handbook of Psychology, Religion and Spirituality: Vol. 1. 2013. McLean, A. (2006). Self-Determination, in Positive Psychology Resources. Retrieved from http://www.centreforconfidence.co.uk/pp/overview.php?p=c21kPTExJnRpZD0wJmlkPTE0MA

44. Mischel, W., Ebbesen, E.B., \& Zeiss, A.M. 1976. Determinants of selective memory about the self. Journal of Consulting and Clinical Psychology. 44(1):92-103.PubMed.

45. Pichon, I., Boccato, G., Saroglou, V. (2007). Nonconsciousness influences of religion on prosociality: A Priming Study. European Journal of Social Psychology, 37, 1032-1045. DOI: 10.1002/ejsp.416

46. Positive Psychology Resources. (2006). Self-Determination. Retrieved from http://www.centreforconfidence.co.uk/pp/overview.php?p=c2lkPTExJnRpZD0wJmlkPTE0MA

47. Pratt, J.B. (1934).The religious Consciousness: a Psychological Study. New York, NY: Macmillan.

48. Psychology. (n.d). Self-Regulation. Retrieved from https://psychology.iresearchnet.com/socialpsychology/self/self-regulation/

49. Rounding, K., Lee, A. \& Jacobson, J.A. (2012). Religion Replenishes self-Control. Psychological Science, Vol. 23, issue 6, 2012.

50. Reis, S.M., \& Greene, M.J. (n.d). Using Self-Regulated Learning to Reverse Underachievement in Talented Students. Reterived from https://gifted.uconn.edu/schoolwide-enrichment-model/selfregulated_learning_reverse_underachievement/

51. Ryan, R. M., Rigby, S., \& King, K. (1993). Two types of religious internalization and their relations to religious orientations and mental health. Journal of Personality and Social Psychology, 65, 586-596. 
52. Ryan, R. M., Deci, E.L. (2000). Intrinsic and Extrinsic Motivations: Classic Definitions and New Directions. Contemporary Educational Psychology, 25, 54-67.

53. SDT:Self-Determination Theory. (n.d). Christian Religious Internalization Scale. Retrieved from http://selfdeterminationtheory.org/self-regulation-questionnaires-religious/

54. Shonkoff JP, Phillips DA, editors. 2000. Acquiring Self-Regulation. Washington (DC): National Research Council (US) and Institute of Medicine (US) Committee on Integrating the Science of Early Childhood Development.

55. Siegel, D. (2012). The Developing Mind: How Relationships and the Brain Interact to Shape Who We Are. New York: Guilford Publications.

56. Smith, T.B., McCullough, M.E., \& Poll, J. (2003). Religiousness and Depression: Evidence for a main effect and the moderating influence of stressful life events. Psychological Bulletin, 129, 614-636.doi:10:1037/00332909.129.4.614

57. Stosny, S. 2011. Self-Regulation. Published at Psychology Today. Retrieved from https://www.psychologytoday.com/blog/anger-in-the-age-entitlement/201110/self-regulation

58. Vlachapoulos, S.P \&Karageorghis, C.L. (2005). Interaction of External, Introjected and Identified Regulation with Intrinsic Motivation in Exercise: Relationships with Exercise Enjoyment. Journal of Applied Behavioral Research . DOI: 10.1111/j.1751-9861.2005.tb00007.x. Retrieved from http://onlinelibrary.wiley.com

59. Wilson, P.M \& Rogers, W.T. (2008). Examining Relationships Between Perceived Psychological Need Satisfaction and Behavioral Regulations in Exercise. Journal of Applied Behavioral Research. DOI: 10.1111/j.1751-9861.2008.00031.x. Retrieved from http://onlinelibrary.wiley.com

60. Wilson, P.M, Rodgers. W.M., Blanchard, Ch.M \& Gessell, J. (2003). The Relationship Between Psychological Needs, Self-Determined Motivation, Exercise Attitudes, and Physical Fitness. 